Interational Archives of
Allergy
Immunology
Int Arch Allergy Immunol 2012;158:157-167

DOI: $\underline{10.1159 / 000331143}$
Received: February 24, 2011

Accepted after revision: July 25, 2011

Published online: January 25, 2012

\title{
Expression and Characterization of Natural-Like Recombinant Der $p 2$ for Sublingual Immunotherapy
}

\author{
Véronique Bordas-Le Floch Laetitia Bussières Sabi Airouche Aurélie Lautrette \\ Julien Bouley Nathalie Berjont Stéphane Horiot Axelle Huet Karine Jain \\ Pierrick Lemoine Henri Chabre Thierry Batard Laurent Mascarell \\ Véronique Baron-Bodo Sophie Tourdot Emmanuel Nony Philippe Moingeon
}

Stallergènes SA, Antony, France

\section{Key Words}

Allergy vaccine $\cdot$ Der p 2 molecules $\cdot$ House dust mite $\cdot$

Recombinant allergen

\begin{abstract}
Background: Recombinant allergens with a native conformation represent an alternative to natural extracts for immunotherapy and diagnostic purposes. Methods: We produced the Der p 2 mite allergen in Pichia pastoris and Escherichia coli. After purification by cation exchange chromatography, recombinant molecules were compared to their natural counterpart based upon structural (disulfide bonds, secondary structure, thermal stability) and immunological properties (antibody reactivity, basophil and T cell activation, tolerance induction in a murine sublingual immunotherapy model). Results: The Der p 2.0101 isoform was confirmed to be prevalent in Dermatophagoides pteronyssinus extracts. It was then produced as a secreted molecule in $P$. pastoris or refolded from E. coli inclusion bodies. The yeastexpressed rDer $\mathrm{p} 2$ molecule exhibits a natural-like disulfide bridge distribution and secondary structure, whereas the E. coli-derived rDer $\mathrm{p} 2$ presents some heterogeneity in cysteine bonds and a lower stability following thermal stress.
\end{abstract}

The two recombinant as well as natural Der $\mathrm{p} 2$ molecules exhibit comparable IgE recognition and activate basophil and CD4+ T cells. Sublingual immunotherapy of nDer $p$ 2sensitized mice using either one of the rDer $p 2$ molecules efficiently decreases airway hyperresponsiveness as well as Th2 responses. Conclusions: Natural and recombinant Der $\mathrm{p} 2$ molecules produced in P. pastoris and E. coli exhibit comparable immunological properties despite distinct structural features. Natural-like cysteine pairing is a critical parameter to identify stable, well-folded and homogenous proteins appropriate for immunotherapy and diagnostic purposes.

Copyright $\odot 2012$ S. Karger AG, Basel

\section{Introduction}

Specific immunotherapy with natural allergens is established as a safe and efficacious treatment for respiratory allergies, both in adults and children [1-10]. Current vaccines are based on complex allergen extracts that are not easy to standardize. In this context, recombinant allergens represent a valid alternative for immunotherapy, as they can be produced using good manufacturing practice-compliant systems in large quantities in the form of

\section{KARGER}

Fax +4161306 1234 E-Mail karger@karger.ch www.karger.com
(C) 2012 S. Karger AG, Basel

$1018-2438 / 12 / 1582-0157 \$ 38.00 / 0$

Accessible online at:

www.karger.com/iaa
Correspondence to: Dr. Philippe Moingeon

Stallergènes $\mathrm{SA}$

6 rue Alexis de Tocqueville

FR-92183 Antony cedex (France)

Tel. +33 1555925 20, E-Mail pmoingeon@ stallergenes.fr 
well-defined molecules [11-14]. In this regard, numerous approaches are focusing on hypoallergenic forms with disrupted IgE binding sites, with the aim of producing safer vaccines with a preserved capacity to induce protective immune responses $[12,15,16]$. However, when considering either diagnostic applications or the sublingual route of immunotherapy, allergens in the most natural conformation are preferred [17]. Indeed, maintaining IgE recognition is thought to facilitate allergen addressing to FceRI-expressing tolerogenic dendritic cells in oral mucosal tissues [18-21].

With the aim of developing a recombinant vaccine to treat allergies to the Dermatophagoides mite species, group 1 and 2 allergens represent highly clinically relevant molecules, as more than $80 \%$ of house-dust-mite (HDM)-allergic patients exhibit elevated seric IgE titers against each of these molecules [22-25]. Given the highsequence homology and thus substantial IgE cross-reactivities between allergens from the closely related species $D$. farinae [24, 26-28], a vaccine comprising only D. pteronyssinus allergens could be considered to treat allergies to either one of these two prominent mite species.

In this study, we focused on the expression and characterization of the Der $\mathrm{p} 2$ allergen for potential pharmaceutical applications. Although Der p 2 has been previously produced in a recombinant form in a variety of expression systems [29-32], as of today, none of these studies has documented a bona fide natural conformation of the molecule to a level fulfilling the requirements for human administration. As Der p 2 exists as a variety of isoforms/variants [33-35], we first selected a prominent isoform following a mass spectrometry (MS) analysis of mite extracts. The Der p 2.0101 isoform was thus produced as a recombinant molecule in both Pichia pastoris ( $\mathrm{rDer} \mathrm{p} 22_{\mathrm{pp}}$ ) and Escherichia coli (rDer p 2 $2_{\mathrm{ec}}$ ) and compared with natural purified Der $\mathrm{p} 2$ in terms of structural and immunological properties.

\section{Materials and Methods}

\section{Natural Der 22 Purification}

Natural Der p 2 was purified from D. pteronyssinus mites cultured at our facilities [36]. Allergen purification was first performed from mite extracts by hydrophobic interaction chromatography using a phenyl sepharose column (GE Healthcare, Saclay, France) and $20 \mathrm{~mm}$ sodium phosphate, $1.8 \mathrm{M}$ ammonium sulphate $\mathrm{pH} 6.2$, as well as $20 \mathrm{~mm}$ sodium phosphate, $5 \%$ isopropanol $\mathrm{pH}$ 7.5 as binding and elution buffers, respectively. Natural Der p 2 in $10 \mathrm{~mm}$ sodium acetate, $0.5 \mathrm{M} \mathrm{NaCl}, \mathrm{pH} 6$ was then loaded onto a SP XL column (GE Healthcare) for further purification, and eluted with $10 \mathrm{~mm}$ sodium acetate, $0.5 \mathrm{M} \mathrm{NaCl} \mathrm{pH} 6$.
Expression and Purification of Recombinant Der $p 2$ in

P. pastoris

A DNA sequence encoding Der p 2.0101 (P49278) was cloned flush with an $\alpha$-factor signal sequence in pPICZ $\alpha$ (Invitrogen, Cergy Pontoise, France) using XhoI and Not I restriction sites. Yeast GS115 and X33 strains were transformed with the resulting plasmid by electroporation using a Gene Pulser Xcell apparatus according to the manufacturer's instructions (Bio-Rad, Marnela-Coquette, France). Transformants selected on $100 \mu \mathrm{g} / \mathrm{ml} \mathrm{zeo-}$ cine YPD plates were grown overnight at $30^{\circ} \mathrm{C}$ in buffered glycerol-complex medium yeast extract $\mathrm{pH} 6$ medium until reaching an $\mathrm{OD}_{600 \mathrm{~nm}}$ of 2-6. Cells were then diluted in buffered methanolcomplex medium yeast extract $\mathrm{pH} 6$ induction medium to an initial $\mathrm{OD}_{600 \mathrm{~nm}}$ of 1 and further grown for $1-6$ days at $30^{\circ} \mathrm{C}$. Culture supernatants were harvested by centrifugation and stored at $-20^{\circ} \mathrm{C}$ until use.

Supernatants were dialyzed against a $10 \mathrm{~mm} \mathrm{NaCl}, 10 \mathrm{~mm}$ sodium acetate, $\mathrm{pH} 5$ binding buffer and applied onto an SP XL column (GE Healthcare). Recombinant Der p 2 pp was eluted with a $500 \mathrm{mM} \mathrm{NaCl}, 10 \mathrm{~mm}$ sodium acetate, $\mathrm{pH} 5.5$ gradient. Fractions containing rDer $\mathrm{p} 2$ pp were pooled and concentrated using an Amicon cell with a 5-kDa cutoff membrane (Millipore, SaintQuentin-en-Yvelines, France). Endotoxin levels in rDer p 2 pp solution $(10 \mu \mathrm{g} / \mathrm{ml})$, measured by a Limulus Amoebocyte Lysate assay, were under $1 \mathrm{EU} / \mathrm{ml}$.

Expression, Refolding and Purification of Recombinant

Derp 2 in E. coli

A DNA sequence encoding mature Der p 2.0101 with a D1S mutation was cloned in pET24a(+) (Novagen, Nottingham, UK) using NdeI and NotI restriction sites. The plasmid was then introduced in BL21 (DE3) cells according to the manufacturer's instructions (Invitrogen) and transformants were selected in the presence of $30 \mu \mathrm{g} / \mathrm{ml}$ kanamycine.

Small-scale expression was performed as previously described [37]. Briefly, overnight starter cultures were diluted in fresh LB medium and further grown until reaching an $\mathrm{OD}_{600 \mathrm{~nm}}$ of $0.4-0.8$. Der $\mathrm{p} 2$ expression was then induced for $4 \mathrm{~h}$ with $1 \mathrm{mM}$ isopropyl $\beta$-D-1-thiogalactopyranoside. Cell pellets were collected by centrifugation and stored at $-20^{\circ} \mathrm{C}$ until use.

Fermentation was further performed at a 2-liter scale in a Biostat Bplus bioreactor (Sartorius Stedim, Aubagne, France). An overnight starter culture was used to inoculate a complex richgrowth medium. During the biomass accumulation phase, cells were manually fed with a glucose-containing feeding solution until reaching an $\mathrm{OD}_{600 \mathrm{~nm}}$ of 15 . Der $\mathrm{p} 2$ expression was then induced for $4 \mathrm{~h}$ with $1 \mathrm{mM}$ isopropyl $\beta$-D-1-thiogalactopyranoside. Cells were pelleted by centrifugation and stored at $-20^{\circ} \mathrm{C}$ until use.

Cell lysis was performed by freeze/thaw cycles and sonication. Inclusion bodies were recovered and washed as described elsewhere [37]. After solubilisation in $8 \mathrm{M}$ urea, refolding was done by rapid dilution in $50 \mathrm{~mm}$ Tris $\mathrm{pH} 8,1 \mathrm{mM}$ EDTA, $50 \mathrm{mM} \mathrm{NaCl}$, $5 \mathrm{~mm}$ reduced glutathione and $500 \mathrm{mM}$ L-arginine. Refolded Der p 2 was dialyzed against $50 \mathrm{~mm}$ Tris, 1 mM EDTA, pH 8 buffer and $10 \mathrm{~mm}$ sodium acetate, $\mathrm{pH}$ 5.5. The protein was subsequently loaded onto a SP FF column (GE Healthcare) and eluted with 10 $\mathrm{mm}$ sodium acetate, $240 \mathrm{mM} \mathrm{NaCl}, \mathrm{pH}$ 5. Endotoxin levels in 10 $\mu \mathrm{g} / \mathrm{ml} \mathrm{rDer} \mathrm{p} 2_{\mathrm{ec}}$ solutions, measured by a Limulus Amoebocyte Lysate assay, ranged from less than 1 to $88 \mathrm{EU} / \mathrm{ml}$. 


\section{Western Blots}

Purified allergens were quantified using Bradford assays. Following SDS-PAGE on 4-12\% Bis-Tris acrylamide gels (Invitrogen), Western blots were performed and revealed with either the Dpx-A9 mouse anti-Der p 2 monoclonal antibody $(0.2 \mu \mathrm{g} / \mathrm{ml}$; Indoor Biotechnologies Limited, Warminster, UK) or a pool of sera obtained from HDM-allergic donors, as previously described [37]. Recombinant Bet v $1(200 \mathrm{ng})[38,39]$ was used as a negative control.

\section{Circular Dichroism}

The higher-order structure of Der p 2 molecules was examined by circular dichroism (CD). Spectroscopic profiling was carried out using a Jasco J-815 CD spectrophotometer (Jasco, Bouguenais, France) against a buffer blank (10 mM sodium acetate, $150 \mathrm{mM} \mathrm{NaCl}, \mathrm{pH}$ 5.0). Eight independent spectral scans were recorded in the 200-260 $\mathrm{nm}$ wavelength range, in 1-mm cuvettes with a scanning speed of $100 \mathrm{~nm} / \mathrm{min}$, a 1-nm bandwidth and a $0.2-\mathrm{nm}$ data pitch, and averaged. The Yang reference algorithm [40] was used to estimate the relative proportion of $\alpha$-helical, $\beta$ sheet, turn and random coil contents. For thermal denaturation experiments, protein samples were heated from 20 to $90^{\circ} \mathrm{C}$ in $10^{\circ} \mathrm{C}$-incremental steps, and three $\mathrm{CD}$ spectra were averaged.

\section{Reversed-Phase Liquid Chromatography-UV-Mass}

Spectrometry Analyses

Mass calculation by reversed-phase liquid chromatographyUV-MS analyses was performed on each of 3 batches of recombinant Der $\mathrm{p} 22_{\mathrm{ec}}$ and Der $\mathrm{p} 2_{\mathrm{pp}}$ molecules. To this end, $5 \mu \mathrm{g}$ Der $\mathrm{p} 2$ were injected onto a $\mathrm{C}_{18}$ HypersilGold $(2.1 \times 200 \mathrm{~mm}, 1.9 \mu \mathrm{m})$ column (ThermoScientific, Courtaboeuf, France), thermostated at $65^{\circ} \mathrm{C}$ and connected to a rapid separation liquid chromatography (RSLC) system (Dionex, Voisins Le Bretonneux, France). An acetonitrile gradient containing $0.1 \% \mathrm{v} / \mathrm{v}$ formic acid was applied over 15 min using an U3000 RSLC chromatographic instrument (Dionex) with a $400 \mu \mathrm{l} \cdot \mathrm{min}^{-1}$ flow rate to ensure proper UV detection at $214 \mathrm{~nm}$. A quadripole-time of flight mass spectrometer (Maxis, Bruker Daltonics, Wissembourg, France) was connected to the RSLC for accurate mass measurement. Mass spectra deconvolution was performed using a MaxEnt algorithm and the following parameters: $13,000-16,000 \mathrm{Da}$, data point spacing auto and resolution 35,000 .

For disulfide bridge mapping, proteins $(15 \mu \mathrm{g})$ were alkylated for 30 min with $15 \mathrm{~mm}$ iodoacetamide in a $75 \mathrm{mM}$ ammonium bicarbonate buffer, then digested with trypsin (Sigma, SaintQuentin Fallavier, France) using a $1 / 25(\mathrm{~m} / \mathrm{m})$ trypsin/Der p 2 ratio. After a 16 -hour digestion at $37^{\circ} \mathrm{C}$, the reaction was stopped by adding $0.5 \%$ TFA. Digests were separated on a $\mathrm{C}_{18}$ Acquity $(\mathrm{BEH} 130,100 \times 2.1 \mathrm{~mm}, 1.7 \mu \mathrm{m})$ column (Waters, Guyancourt, France) with a 2 -step linear gradient from 0 to $55 \%$ acetonitrile (0.1\% TFA) over 50 min, using a U3000 RSLC chromatographic apparatus (Dionex). Tandem MS acquisition was performed on a quadripole-time of flight mass spectrometer (Maxis).

\section{Basophil Activation Tests}

Basophil activation was assessed with an FC500 cytometry apparatus (Beckman Coulter, Villepinte, France) using the Allergenicity kit (Beckman Coulter) to measure the surface expression of the activation marker CD203c, as previously described [41]. Whole blood samples treated with acid citrate dextrose were ob- tained from $6 \mathrm{HDM}$-allergic donors and incubated at $37^{\circ} \mathrm{C}$ for 15 $\mathrm{min}$ in the presence of increasing concentrations (0.064-1,000 ng/ $\mathrm{ml}$ ) of natural or recombinant Der p 2 molecules. Whole blood cells incubated with either PBS or anti-IgE antibodies were used as negative and positive controls, respectively. Activated basophils were detected after the exclusion of T lymphocytes (CD3+ cells) as CRTH2 $2^{+}$CD203 $3^{\text {high }}$ cells.

\section{ELISA Inhibition Assays}

The ability of the various Der p 2 molecules to inhibit IgE binding to nDer $\mathrm{p} 2$ was examined using ELISA inhibition with a pool of sera obtained from $12 \mathrm{HDM}$-allergic patients. Purified natural Der p $2(10 \mu \mathrm{g} / \mathrm{ml})$ was coated overnight in a 0.1 -M sodium carbonate-bicarbonate $\mathrm{pH} 9.5$ buffer in microtiter plates. The serum pool was mixed with increasing concentrations of either natural or recombinant Der p 2 molecules (ranging from 0.002 to 175 $\mu \mathrm{g} / \mathrm{ml}$ ) and incubated overnight at $4{ }^{\circ} \mathrm{C}$ with nDer $\mathrm{p}$ 2-coated plates. After 5 washes with PBS $0.1 \%$ Tween, bound IgEs were detected using a 1:1,000 dilution of a horseradish peroxidase-conjugated anti-human IgE antibody (Calbiochem, Nottingham, UK) and OPD substrate (Sigma). The reaction was stopped with $3 \mathrm{M}$ $\mathrm{HCl}$, and plates were read at $492 \mathrm{~nm}$ on a Multiskan ascent spectrophotometer (Labsystems, Saint Herblain, France). Percentages of inhibition were calculated as $100 \times\left[\left(\mathrm{OD}_{\mathrm{NI}}-\mathrm{OD}_{\mathrm{I}}\right) / \mathrm{OD}_{\mathrm{NI}}\right]$ with $\mathrm{OD}_{\mathrm{NI}}$ and $\mathrm{OD}_{\mathrm{I}}$ being the ODs measured with the non-inhibited and inhibited sera pools, respectively.

\section{Sublingual Immunotherapy of $n$ Der $p$ 2-Sensitized Mice}

$\mathrm{BALB} / \mathrm{c}$ mice sensitization was performed according to the protocol previously described [42]. They were sensitized by 2 intraperitoneal injections at 14 -day intervals with $10 \mu \mathrm{g}$ nDer $\mathrm{p} 2$ adsorbed on $2 \mathrm{mg}$ of alum, then exposed daily to $D$. pteronyssinus extract aerosols (corresponding to 1-mg Der p 2 doses) for a week. Sensitized mice were randomized into treatment groups with 6 mice per group, respectively. Unsensitized healthy mice were used as an additional control group. The mice were treated sublingually twice a week for 8 weeks with either vehicle (PBS only), rDer $\mathrm{p}$ $2_{\mathrm{ec}}$ or rDer p $2_{\mathrm{pp}}(50 \mu \mathrm{g}$ in $50 \mu \mathrm{l}$ PBS). Following treatment, they were challenged with $D$. pteronyssinus extract (using doses corresponding to $1 \mathrm{mg}$ Der $\mathrm{p} 2$ per aerosol) on two consecutive days. Airway hyperresponsiveness (AHR) was assessed $24 \mathrm{~h}$ after the last challenge as described elsewhere [42], using whole body plethysmography (Buxco Europe Ltd, Winchester, UK) in the presence of either $50 \mathrm{mg} / \mathrm{ml}$ methacholine or PBS, and expressed as a Penh Index. Penh indexes were calculated as ratios with baseline Penh after exposure to nebulized PBS. Statistical significance was evaluated with Mann-Whitney tests using 95\% confidence intervals.

\section{Assessment of Immune Responses in the Lungs}

Bronchoalveolar lavage was performed by flushing out the lungs with $1.2 \mathrm{ml}$ PBS via a tracheal cannula. Lavage fluids were then centrifuged at $800 \mathrm{~g}$ for $5 \mathrm{~min}$ at $4^{\circ} \mathrm{C}$. Cell pellets were resuspended in $0.6 \mathrm{ml} \mathrm{PBS}$, spun onto glass slides by cytocentrifugation, fixed and stained with May-Grünwald Giemsa (Réactifs RAL, Martillac, France) prior to differential cell counts.

To assess $\mathrm{T}$ cell responses, lung cells from nDer $\mathrm{p} 2$-sensitized mice were recovered after treatment with either PBS, rDer $\mathrm{p} 2_{\mathrm{ec}}$ or rDer p $2_{\text {pp }}$ and cultured $\left(1 \times 10^{6}\right.$ per well) for $72 \mathrm{~h}$ at $37^{\circ} \mathrm{C}$, in $5 \%$ $\mathrm{CO}_{2} / 95 \%$ air, in RPMI 1640 medium supplemented with glutamine (PAA laboratories, Les Mureaux, France), penicillin/strepto- 
Table 1. Isoform polymorphism and disulfide mapping within natural and recombinant Der $\mathrm{p} 2$ molecules

\begin{tabular}{|c|c|c|c|c|c|c|c|}
\hline & Isoform & $\begin{array}{l}\text { Molecular mass (Da) } \\
\text { (theoretical) }\end{array}$ & $\begin{array}{l}\text { Sequence } \\
\text { variation }^{\mathrm{a}}\end{array}$ & $\begin{array}{l}\mathrm{N} \text {-terminal } \\
\text { sequence }\end{array}$ & Secondary structure & $\begin{array}{l}\text { Expected disul- } \\
\text { fide bridges }^{c}\end{array}$ & $\begin{array}{l}\text { Mispaired } \\
\text { disulfide bridges }\end{array}$ \\
\hline nDer p 2 & $\begin{array}{l}2.0101 \\
2.0105 \\
2.0109 \\
2.0104\end{array}$ & $\begin{array}{c}14,115.168 \\
(14,115.177) \\
14,115.168 \\
(14,115.177) \\
14,082.190 \\
(14,082.223) \\
14,096.181 \\
(14,096.234)\end{array}$ & $\begin{array}{l}\text { V40L T47S } \\
\text { M111L D114N } \\
\text { T47S } \\
\text { V40L T47S } \\
\text { M111L D114N }\end{array}$ & DQVDVK & $\begin{array}{l}\alpha \text {-helix: } 34.2 \% \\
\beta \text {-sheet: } 50.6 \% \\
\text { turn: } 1.8 \% \\
\text { random coil :13.4\% }\end{array}$ & yes & none detected \\
\hline rDer p $2_{\mathrm{ec}}$ & 2.0101 & $\begin{array}{c}14,087.169 \\
(14,087.182)\end{array}$ & $\mathrm{D} 1 \mathrm{~S}^{\mathrm{b}}$ & $S^{b} Q V D V K$ & $\begin{array}{l}\alpha \text {-helix: } 52.7 \% \\
\beta \text {-sheet: } 46.7 \% \\
\text { turn: } 0 \% \\
\text { random coil: } 0.6 \%\end{array}$ & yes & $\begin{array}{l}30 \text { to } 70 \% \\
\text { e.g.C21-C119 } \\
\text { C8-C78 } \\
\text { C73-C119 }\end{array}$ \\
\hline rDer p $2_{\mathrm{pp}}$ & 2.0101 & $\begin{array}{c}14,115.208 \\
(14,115.177)\end{array}$ & & DQVDVK & $\begin{array}{l}\alpha \text {-helix: } 36.1 \% \\
\beta \text {-sheet: } 59.6 \% \\
\text { turn: } 0 \% \\
\text { random coil: } 4.3 \%\end{array}$ & yes & none detected \\
\hline
\end{tabular}

Summary of experimental masses, sequence polymorphisms, mutations, amino-terminal sequence and cysteine bridge distribution obtained for natural and recombinant Der p 2 molecules. Results are compiled from experiments conducted with 11 batches of purified nDer $\mathrm{p} 2$ and 3 batches each of rDer $\mathrm{p} 2 \mathrm{ec}_{\mathrm{ec}}$ and rDer $\mathrm{p} 2 \mathrm{pp}$. The relative amount of isoform 2.0101 within 3 independent batches of nDer p 2 was found to be more than $50 \%$. Percentages of secondary structure elements were estimated on $\mathrm{CD}$ spectra using Yang's algorithm. a Taking isoform 0101 sequence as a reference. Amino acid substitutions were determined by MS.

${ }^{b}$ a D/S mutation was introduced to facilitate cleavage of the amino-terminal methionine.

${ }^{\mathrm{c}} \mathrm{C} 21-\mathrm{C} 27, \mathrm{C} 8-\mathrm{C} 119, \mathrm{C} 71-\mathrm{C} 78$, with numbering relative to the amino-acid sequence of mature Der $\mathrm{p} 2$. mycin (Fisher Bioblock, Illkirch, France) and 10\% fetal calf bovine serum (Gentaur, Brussels, Belgium) in the presence of $10 \mu \mathrm{g} / \mathrm{ml}$ of either recombinant, natural Der $\mathrm{p} 2$ or purified $\mathrm{nDac} g 1$ allergen and medium as controls. After 3 days, IL-5, IL-10 and IL-13 levels were measured in culture supernatants by cytometric bead arrays (BD Biosciences, Le Pont de Claix, France) according to the manufacturer's recommendations. Statistical significances were evaluated with Mann-Whitney tests using 95\% confidence intervals.

\section{Results}

Expression of Recombinant Der p 2 in P. Pastoris and E. coli

Natural Der p 2 was purified from a D. pteronyssinus extract by hydrophobic, then ion exchange chromatography and further analyzed by MS to investigate isoform variability and prevalence. As shown in table 1, at least four distinct isoforms were concomitantly found in the mite extract, with isoform 2.0101 being one of the most prominent; it was thus selected as a reference natural molecule. Corresponding cDNAs were expressed in $P$. pastoris and E. coli as described in Methods, leading to rDer $\mathrm{p} 2_{\mathrm{pp}}$ and $\mathrm{rDer} \mathrm{p} 2_{\mathrm{ec}}$, respectively.

rDer $\mathrm{p} 2$ p was produced as a secreted molecule, whereas rDer $\mathrm{p} 2$ ec was expressed as inclusion bodies. After solubilisation, the latter was refolded by a rapid dilution method. Both recombinant molecules were purified by cation exchange chromatography as described in Methods, with a purity superior to $90 \%$. Yields were in the order of 60-70 mg/l Der p 2 after purification and concentration in both expression systems. Antibody recognition of these recombinant Der p 2 molecules was tested by immunoblot using both specific murine monoclonal antibodies directed against natural Der p 2 and human IgEs from HDM-allergic patients. In these experiments, natural Der $\mathrm{p} 2$ and rBet $\mathrm{v} 1$ were used as positive and negative controls, respectively. All molecules reacted similarly with Der p 2-specific monoclonal and IgE antibodies as a single $14 \mathrm{kDa}$ band (fig. 1). 


\section{Physicochemical and Structural Characterization of}

Recombinant Der p 2 Molecules

Precise masses of rDer p 2 molecules were determined by MS and were confirmed to be in good agreement with the theoretical mass, with less than 3 ppm mass differences (table 1). Furthermore, exact mass data indicated that $\mathrm{N}$-terminal ends of the two recombinant proteins were correctly processed and that the amino-terminal methionine was removed in E. coli.

We subsequently compared secondary structures of the three Der p 2 molecules using CD. As illustrated in figure $2 \mathrm{a}$, nDer $\mathrm{p} 2$ and rDer $\mathrm{p} 2$ pp displayed similar $\mathrm{CD}$ spectra. The E. coli-expressed rDer p $2_{\mathrm{ec}}$ molecule was also clearly folded, albeit with a different secondary structure, including most particularly a lower $\beta$-sheet content (table 1), when compared with nDer $\mathrm{p} 2$.

Thermal denaturation experiments were conducted between 20 and $90^{\circ} \mathrm{C}$ to compare the stability of the molecules. As shown in figure $2 \mathrm{~b}$ and $\mathrm{c}$, respectively, nDer $\mathrm{p} 2$ and rDer $\mathrm{p} 22_{\mathrm{pp}}$ spectra did not change significantly when the temperature was raised, confirming a high stability for these two molecules. In contrast, thermal denaturation of rDer $\mathrm{p} 2_{\mathrm{ec}}$ resulted in substantial changes in the $\mathrm{CD}$ spectrum, demonstrating a loss of structure above $70^{\circ} \mathrm{C}$ (fig. $2 \mathrm{~d}$ ). In addition, $\mathrm{CD}$ spectra acquired before heating and after cooling rDer p $2_{\mathrm{ec}}$ back to $20^{\circ} \mathrm{C}$ were clearly distinct (fig. 2e), indicating that the molecule could not refold properly following heat denaturation.

We further explored the distribution of disulfide bridges by liquid chromatography tandem MS. The three expected disulfide bonds (C8-C119, C16-C27, C73-C78) reported in the literature $[43,44]$ were present in both the natural and the two recombinant allergens. However, some cysteine mispairings (representing $30-70 \%$ of cysteine bridges) were also found in the E. coli-expressed molecule, thus indicating a heterogeneous folding when compared to rDer $\mathrm{p} 2_{\mathrm{pp}}$ and $\mathrm{nDer} \mathrm{p} 2$ (table 1 ). Noteworthy no intermolecular bridges were detected. Consistent with the latter observation, the two rDer $\mathrm{p} 2$ as well as nDer $\mathrm{p} 2$ were confirmed to be mainly monomeric, when tested by size exclusion chromatography (data not shown).

\section{Immunogenicity of Recombinant Der p 2 Molecules}

The two rDer $\mathrm{p} 2$ molecules were compared with purified nDer $\mathrm{p} 2$ for their capacity to activate peripheral blood basophils obtained from mite-sensitized patients $(\mathrm{n}=3)$. The upregulation of the CD203c activation marker was measured by FACS after incubating basophils with serial concentrations $(0.064-1,000 \mathrm{ng} / \mathrm{ml})$ of each of the allergens. In agreement with the IgE reactivity patterns

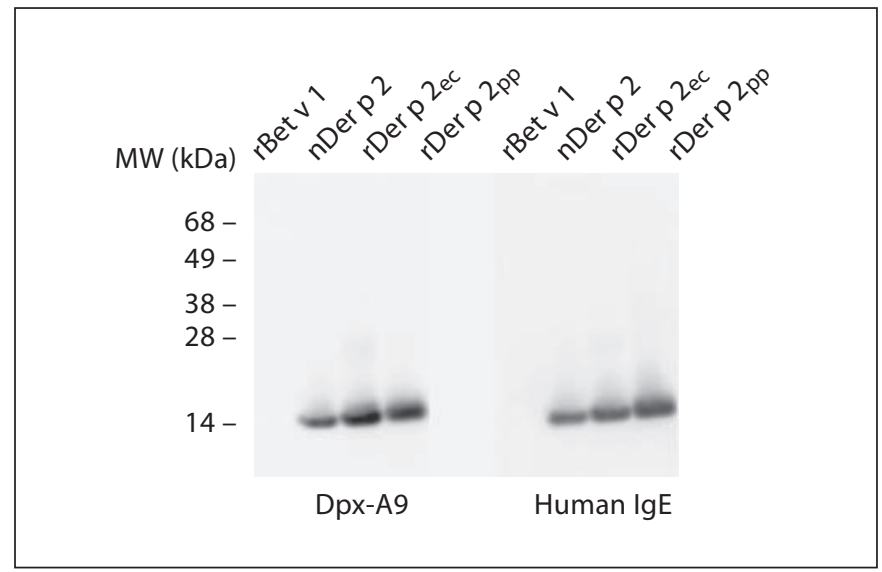

Fig. 1. Immunoblot analysis of Der p 2 produced in E. coli and $P$. pastoris. Western blot analysis of purified natural and recombinant Der p 2 (200 ng/lane) was performed under nonreducing conditions with the specific DpX-A9 murine monoclonal antibody and IgEs from a pool of sera obtained from HDM-allergic patients. Purified rBet v 1 (200 ng) was used as a negative control.

reported in figure 1 , the two rDer $\mathrm{p} 2$ molecules were able to trigger basophil activation in a comparable manner to nDer p 2 (fig. 3a).

We further compared the ability of recombinant Der $\mathrm{p}$ 2 molecules to inhibit IgE binding to nDer p 2. A pool of sera obtained from HDM-allergic donors was incubated with $\mathrm{nDer} \mathrm{p} 2$-coated plates in the presence of increasing concentrations of either rDer $\mathrm{p} 2_{\mathrm{pp}}$, rDer $\mathrm{p} 2_{\mathrm{ec}}$ or $\mathrm{nDer} \mathrm{p}$ 2 , prior to the detection of bound IgEs. As shown in figure $3 \mathrm{~b}$, such inhibition experiments established that $\mathrm{rDer} \mathrm{p} 2 \mathrm{ec}$ and $\mathrm{rDer} \mathrm{p} 22_{\mathrm{pp}}$ display similar IgE binding, albeit lower than their natural counterpart. Similar experiments performed with individual sera further confirmed a higher reactivity of nDer $\mathrm{p} 2$ when compared to the recombinant molecules (data not shown). This superior reactivity of nDer $\mathrm{p} 2$ is likely a consequence of the IgE recognition of multiple isoforms distinct from isoform 2.0101.

The $\mathrm{T}$ cell recognition of the three Der $\mathrm{p} 2$ molecules was also compared. To this end, lung cells were recovered from nDer $\mathrm{p} 2$-sensitized mice and restimulated in vitro for 3 days with either $10 \mu \mathrm{g} / \mathrm{ml} \mathrm{nDer} \mathrm{p} \mathrm{2,} \mathrm{rDer} \mathrm{p} 2_{\mathrm{ec}}$ or rDer $\mathrm{p} 2_{\mathrm{pp}}$, prior to measuring IL-5, IL-10 and IL-13 levels in culture supernatants. As illustrated in figure 4, all Der p 2 molecules induced a readily detectable production of the three cytokines by T cells. Natural Der p 2 consistently induced the highest cytokine levels, likely due to the recognition of multiple isoforms beyond isoform 2.0101 . 


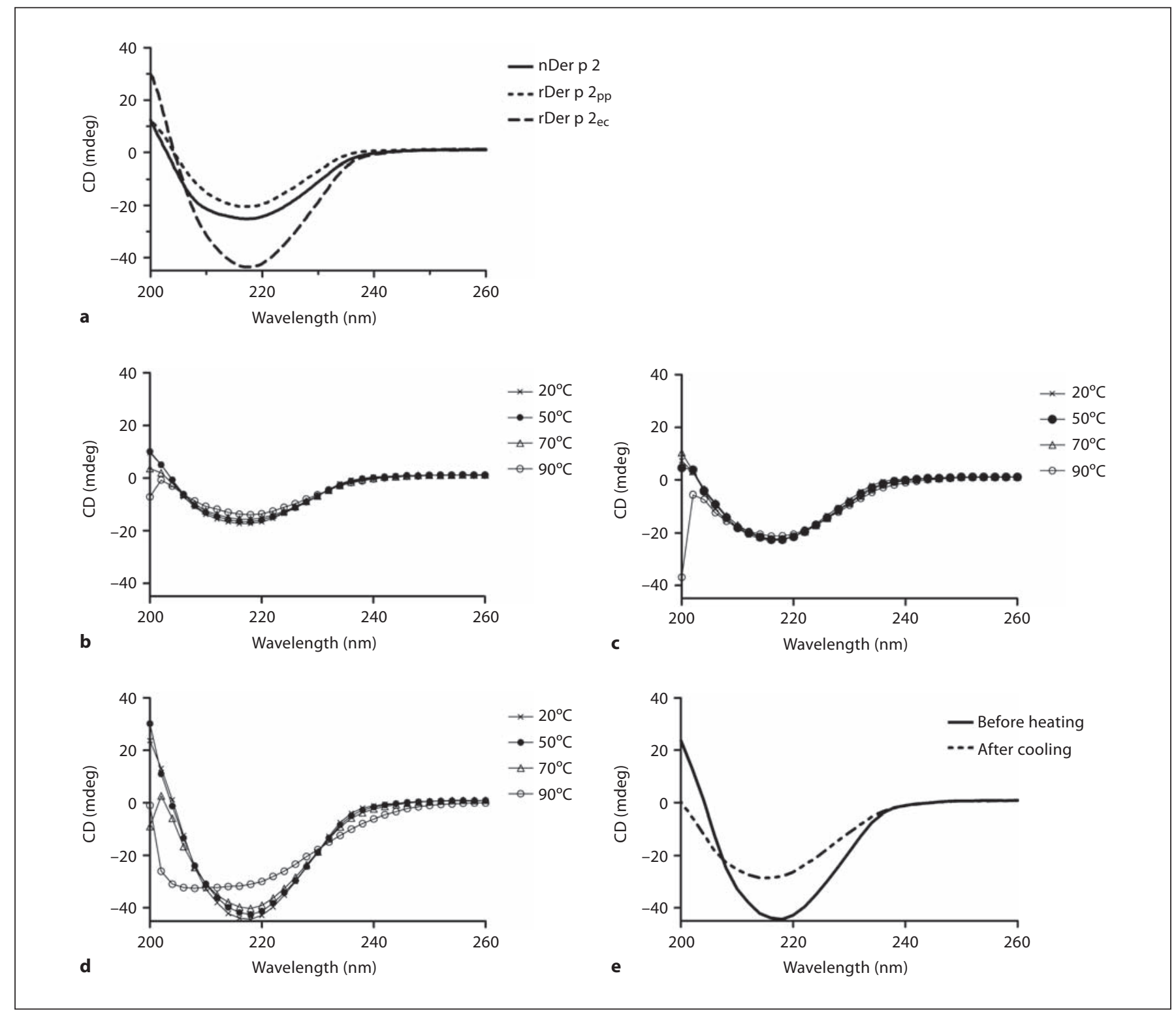

Fig. 2. Secondary structure analysis by CD spectroscopy. Natural and recombinant Der p $2(300 \mu \mathrm{g} / \mathrm{ml})$ were submitted to CD spectroscopy (a). Thermal stability of nDer p 2 (b), rDer p $2_{\mathrm{pp}}$ (c) and rDer p $2_{\mathrm{ec}}$ (d) spectra were recorded at $20^{\circ} \mathrm{C}$ as the average of 8 scans in the wavelength range of 200-260 nm. e Refolding after thermal denaturation of rDer $\mathrm{p} 2 \mathrm{ec}_{\mathrm{c}}$ was assessed by measuring CD spectra after heating the protein with $10^{\circ} \mathrm{C}$-incremental-steps and cooling back to $20^{\circ} \mathrm{C}$. Resulting spectra were obtained as the average of 3 scans.
Tolerance Induction by Sublingual Immunotherapy in a Murine Asthma Model

We subsequently assessed whether sublingual immunotherapy (SLIT) with rDer $\mathrm{p} 2_{\mathrm{ec}}$ or rDer $\mathrm{p} 2_{\mathrm{pp}}$ could desensitize nDer $\mathrm{p}$ 2-allergic mice. Mice were first sensitized with natural purified Der p 2 via the intraperitoneal route prior to challenges with aerosols of $D$. pteronyssinus extracts, as described in Methods. Animals were subsequently treated sublingually twice a week for 8 weeks with PBS or $50 \mu \mathrm{g}$ of either recombinant Der p 2 molecule per dose. As illustrated in figure 5 (a, f), AHR was significantly reduced following SLIT with either $r$ Der $\mathrm{p} 2_{\text {ec }}$ or Der $\mathrm{p} 2_{\mathrm{pp}}$, respectively, when compared to vehicle treatment ( $\mathrm{p}<0.05)$, although not to baseline levels ob- 


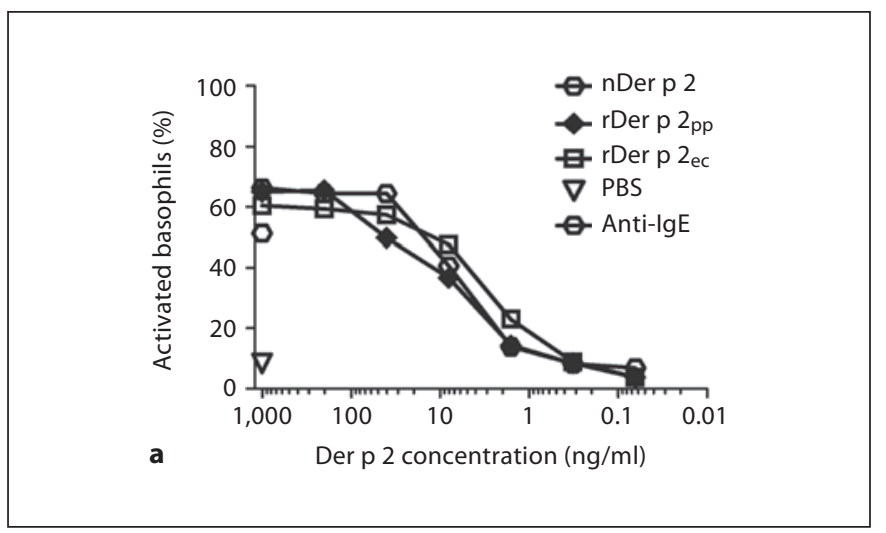

Fig. 3. a Immunological characterization of rDer p 2. IgE binding was investigated by basophil activation and ELISA inhibition assays. Percentages of activated basophils were measured after exposure to varying concentrations of recombinant or natural Der p $2(0.064-1,000 \mathrm{ng} / \mathrm{ml})$. Data are represented as mean percentages of activated basophils obtained from $6 \mathrm{HDM}$-allergic donors. Differences at each dilution point are not statistically significant (Mann-Whitney statistical test with 95\% confi-

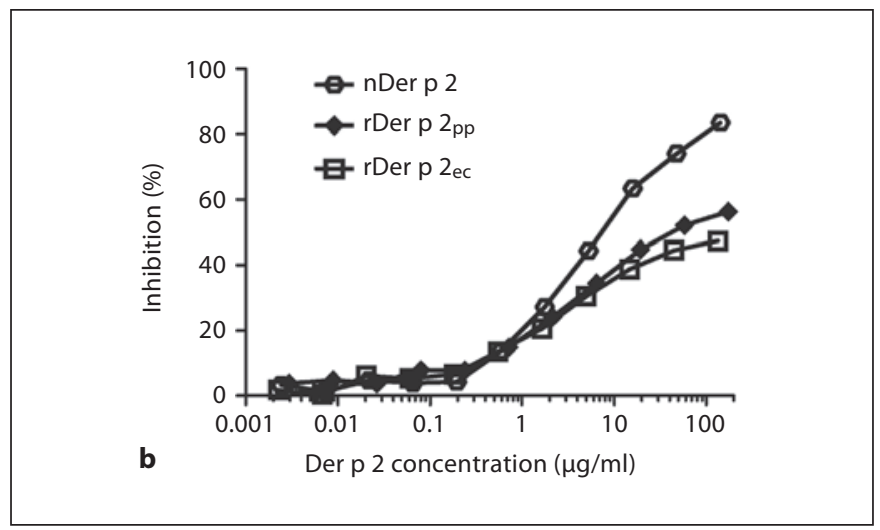

dence intervals). b IgE binding to nDer p 2 was inhibited by natural and recombinant Der p 2 molecules. A pool of sera obtained from $12 \mathrm{HDM}$-allergic donors was mixed with increasing amounts of natural or recombinant allergens (ranging from 0.002 to $175 \mu \mathrm{g} / \mathrm{ml}$ ) and incubated with plates coated overnight with nDer p $2(10 \mu \mathrm{g} / \mathrm{ml})$. Results are expressed as percentages of IgE binding inhibition and are representative of 2 independent experiments.

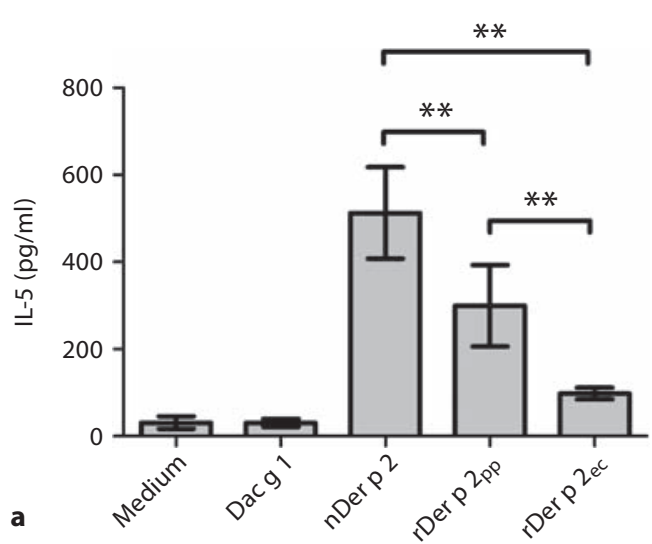

Fig. 4. T cell recognition of Der p 2 molecules. Secretion of IL-5 (a), IL-10 (b) and IL-13 (c) cytokines by lung T cells recovered from 6 Der $\mathrm{p} 2$-sensitized mice were measured by cytometric bead array assays, after a 3 -day in vitro restimulation with $10 \mu \mathrm{g} / \mathrm{ml}$ of the various Der p 2 molecules. Restimulations with growth medium and the irrelevant natural purified Dac g 1 allergen $(10 \mu \mathrm{g} /$ $\mathrm{ml}$ ) were used as negative controls. Data are expressed as the mean +/- SEM values obtained from 6 Der $\mathrm{p} 2$-sensitized mice and are representative of 2 independent experiments. n.s. = Not significant. ${ }^{*} \mathrm{p}<0.05,{ }^{* *} \mathrm{p}<0.01$ and ${ }^{* * *} \mathrm{p}<0.001$, using Mann-Whitney statistical tests with $95 \%$ confidence intervals.
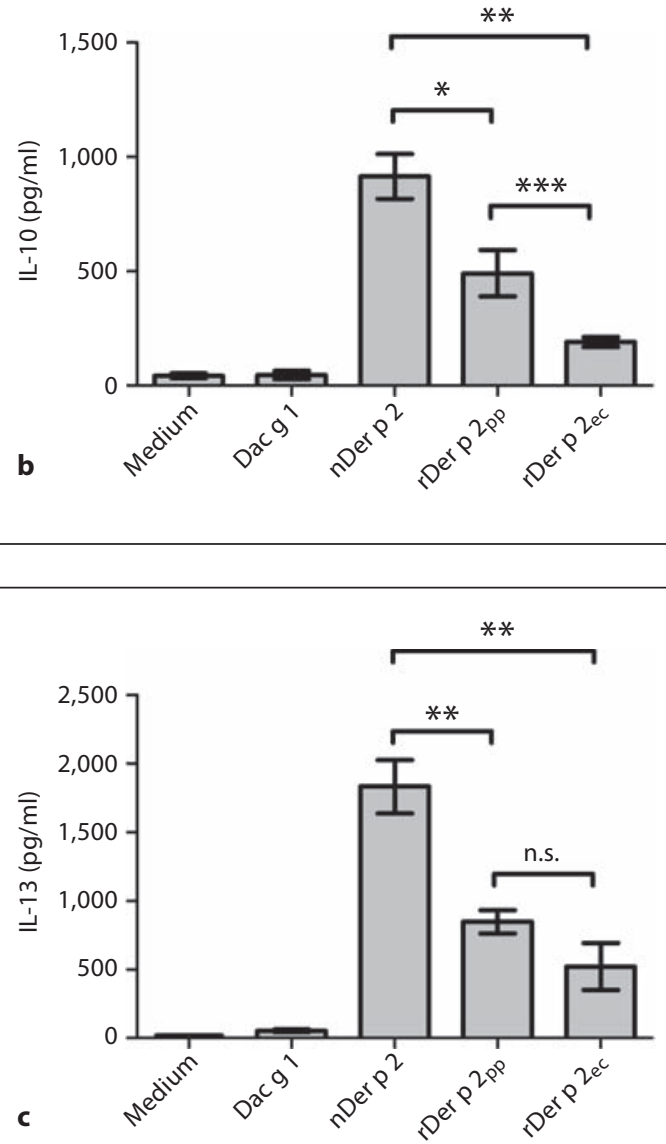

Int Arch Allergy Immunol 2012;158:157-167 


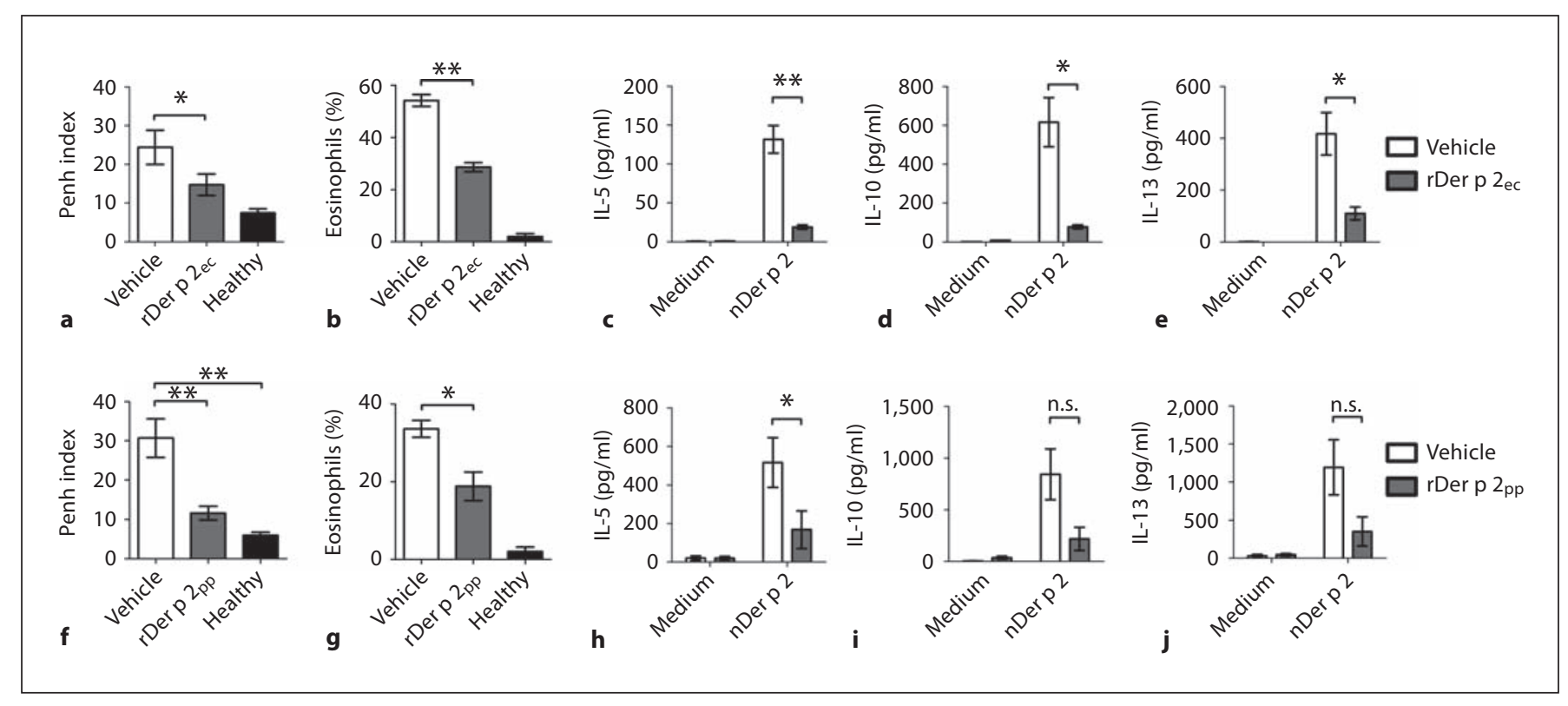

Fig. 5. Desensitization of nDer $\mathrm{p}$ 2-allergic mice by sublingual treatment with either $\mathrm{rDer} \mathrm{p} 2_{\mathrm{ec}}$ or rDer $\mathrm{p} 2_{\mathrm{pp}}$. Mice were sensitized twice with $10 \mu \mathrm{g}$ purified nDer $\mathrm{p} 2$ adsorbed on alum followed by aerosol challenges then treated sublingually with vehicle (PBS) or $50 \mu \mathrm{g}$ rDer p $2_{\mathrm{ec}}$ or Der p $2_{\mathrm{pp}}$, twice a week for 8 weeks. After challenges with aerosols of $D$. pteronyssinus extract, AHR, lung inflammation and rDer $\mathrm{p} 2$-specific $\mathrm{T}$ cell responses were investigated. Results obtained with rDer $\mathrm{p} 2_{\mathrm{ec}}$ and $\mathrm{rDer} \mathrm{p} 2_{\mathrm{pp}}$ are presented in upper and lower panels, respectively. a, f AHR to $50 \mathrm{mg} / \mathrm{ml}$ methacholine was assessed by whole body plethysmography and expressed as a Penh Index. b, g Eosinophilia was measured in bronchoalveolar lavage. Lung cells recovered from mice after SLIT with vehicle, and either rDer $\mathrm{p} 2_{\mathrm{ec}}$ or rDer $\mathrm{p} 2_{\mathrm{pp}}$ were restimulated in vitro with $10 \mu \mathrm{g} / \mathrm{ml} \mathrm{nDer} \mathrm{p} 2$ or medium alone. IL-5 (c, h), IL-10 (d, i), and IL-13 (e, j) secretion was analyzed in supernatants by cytometric bead array assays. Data are expressed as mean + - SEM values obtained from groups of 6 sensitized and 5 healthy mice, respectively. Data are representative of 2 independent experiments for $\mathrm{rDer} \mathrm{p} 2 \mathrm{ec}_{\mathrm{ec}}$ (irrespective of endotoxin content) and 1 for rDer p 2 pp. n.s. $=$ Not significant. ${ }^{*} \mathrm{p}<0.05$ and ${ }^{* *} \mathrm{p}<0.01$ compared with PBS-desensitized mice using Mann-Whitney statistical tests with $95 \%$ confidence intervals. served in unsensitized (i.e. healthy) animals used as controls in these experiments. This reduction of AHR was associated with a significant decrease of eosinophils in bronchoalveolar lavage (fig. 5b, g). Cytokine secretion was measured in lung $\mathrm{T}$ cells recovered from mice after SLIT with PBS, rDer $\mathrm{p} 2_{\mathrm{ec}}$ or rDer $\mathrm{p} 2_{\mathrm{pp}}$ as described in Methods. IL-5, IL-10 and IL-13 secretion by $\mathrm{T}$ cells decreased in mice treated sublingually with either one of the recombinant Der p 2 molecules when compared to PBS (fig. 5c-e, h-j).

\section{Discussion}

Allergen-specific immunotherapy is established as a safe and efficacious treatment for type I allergies against venoms, pollens and mites $[1-10,45]$. Although natural extracts are currently used for immunotherapy, recombinant allergens are being considered as an alternative
$[11,12,46]$ with some advantages over natural allergens. They can be produced in a reproducible way as highly pure and well-defined molecules with a high batch-tobatch consistency. Also, recombinant technologies allow the production of modified (e.g. hypoallergenic) forms as well as natural-like allergens. The latter represent a preferred option for both diagnostic and SLIT purposes $[17,47]$.

With the aim of developing a recombinant sublingual mite allergy vaccine, we focused on the expression of Der p 2 with characteristics similar to its natural counterpart. Although at least 14 natural Der p 2 isoforms diverging by only a few point substitutions have been described so far [33, 35], our analysis by MS established Der p 2.0101 as a main isoform in $D$. pteronyssinus extracts besides variants 0104 and 0109 , in agreement with previous reports $[33,48]$. We thus, produced two recombinant Der $\mathrm{p}$ 2.0101 molecules in P. pastoris and E. coli and compared them after purification with respect to their structural 
and immunological properties, using natural purified Der $\mathrm{p} 2$ as a reference.

Der $\mathrm{p} 2$ expression in E. coli resulted in the formation of inclusion bodies, whereas the expression in P. pastoris yielded a soluble protein. Both recombinant molecules were similarly recognized by Der $\mathrm{p} 2$ 2-specific murine monoclonal antibodies as well as IgEs from HDM-allergic patients. Furthermore, they were comparable in their capacity to trigger basophil activation. The three Der $\mathrm{p} 2 \mathrm{~mol}-$ ecules were also recognized by murine Th2 cells, albeit at various levels, possibly reflecting differences in isoform content or capture/processing of these molecules by antigen-presenting cells. Moreover, the sublingual administration of rDer $\mathrm{p} 2_{\mathrm{ec}}$ or rDer $\mathrm{p} 2_{\mathrm{pp}}$ significantly desensitized nDer $\mathrm{p}$ 2-allergic mice, as indicated by a decrease in both AHR and established allergen-specific Th2 responses.

Other studies reported a successful expression of recombinant Der $\mathrm{p} 2$ in E. coli, alone or as a fusion protein with glutathione-S-transferase or Der p 1 [29, 37, 49-51] as well as in eukaryotic hosts such as Saccharomyces cerevisiae [30,52] and tobacco cells [32]. Some of these molecules were found to resemble the natural counterpart in terms of antigenic properties. However, no detailed analyses were conducted to document molecular homogeneity and stability, which both represent critical properties to warrant pharmaceutical development. More specifically, engagement of the six Der p 2 cysteine into three disulfide bonds residues (C21-C27, C8-C119, C71-C78) $[43,44]$ is critical to establish the 3 -dimensional structure of the molecule and as such to stabilize antigenic determinants $[53,54]$.

In our study, the mapping of cysteine bridges revealed that Der $\mathrm{p} 2_{\mathrm{pp}}$ and Der $\mathrm{p} 2_{\mathrm{ec}}$ recombinant molecules pos- sess the expected disulfide bonds. Nonetheless, rDer $\mathrm{p}$ $2_{\text {ec }}$ presents some heterogeneity, with evidence for additional mispaired disulfide bonds. In agreement with these results, secondary structure and thermal stability analyses by CD spectroscopy confirmed that all molecules exhibit a comparable secondary structure, but that rDer $\mathrm{p} 2_{\mathrm{pp}}$ and nDer $\mathrm{p} 2$ are more stable than rDer $\mathrm{p} 2_{\mathrm{ec}}$. Altogether, our data demonstrate that the rDer $\mathrm{p} 2$ produced in $P$. pastoris more closely resembles nDer $\mathrm{p} 2$ when compared to the E. coli-derived $\mathrm{rDer} \mathrm{p} 2$. These results differ from those obtained in a recent study indicating that Der $\mathrm{p} 2$ secreted by $P$. pastoris has a mainly unordered structure [31]. Explanations for such discrepancies are unclear but may originate from differences in yeast strains as well as the expression and purification protocols used.

One important observation in our study is that immunoreactivity profiles are not very discriminating, even when significant structural differences are detected between molecules. Along with other authors, we reported previously that the immunoreactivity and allergenicity of the Der p 2 molecule are still preserved to some extent despite incorrect folding $[31,37,51,53]$, likely due to the presence of linear IgE epitopes [55]. Our results confirm a direct link between correct cysteine pairing and both molecular homogeneity and stability evaluated by resistance to heat denaturation. Thus, we conclude that P. pastoris is a better expression host than $E$. coli for the production of natural-like Der $\mathrm{p}$ 2. In general, documenting proper cysteine pairing is critical for selecting recombinant allergens to be used for immunotherapy and diagnostic purposes in humans, with specific requirements regarding native structure, stability and molecular homogeneity.

\section{References}

1 Canonica GW, Bousquet J, Casale T, Lockey RF, Baena-Cagnani CE, Pawankar R, Potter PC, Bousquet PJ, Cox LS, Durham SR, Nelson HS, Passalacqua G, Ryan DP, Brozek JL, Compalati E, Dahl R, Delgado L, van Wijk RG, Gower RG, Ledford DK, Filho NR, Valovirta EJ, Yusuf OM, Zuberbier T, Akhanda W, Almarales RC, Ansotegui I, Bonifazi F, Ceuppens J, Chivato T, Dimova D, Dumitrascu D, Fontana L, Katelaris CH, Kaulsay R, Kuna P, Larenas-Linnemann D, Manoussakis M, Nekam K, Nunes C, O’Hehir R, Olaguibel JM, Onder NB, Park JW, Priftanji A, Puy R, Sarmiento L, Scadding G, Schmid-Grendelmeier P, Seberova E, Sepiashvili R, Sole D, Togias A, Tomino C, Toskala E, Van Beever $\mathrm{H}$,
Vieths S: Sub-lingual immunotherapy: World Allergy Organization position paper 2009. Allergy 2009;64(suppl 91):1-59.

-2 Didier A, Malling HJ, Worm M, Horak F, Jager S, Montagut A, Andre C, de Beaumont O, Melac M: Optimal dose, efficacy, and safety of once-daily sublingual immunotherapy with a 5 -grass pollen tablet for seasonal allergic rhinitis. J Allergy Clin Immunol 2007;120:1338-1345.

3 Dahl R, Kapp A, Colombo G, de Monchy JG, Rak S, Emminger W, Rivas MF, Ribel M, Durham SR: Efficacy and safety of sublingual immunotherapy with grass allergen tablets for seasonal allergic rhinoconjunctivitis. J Allergy Clin Immunol 2006;118:434-440.
4 Wilson DR, Lima MT, Durham SR: Sublingual immunotherapy for allergic rhinitis: systematic review and meta-analysis. Allergy 2005;60:4-12.

-5 Passalacqua G, Guerra L, Pasquali M, Lombardi C, Canonica GW: Efficacy and safety of sublingual immunotherapy. Ann Allergy Asthma Immunol 2004;93:3-12.

6 Moller C, Dreborg S, Ferdousi HA, Halken S, Host A, Jacobsen L, Koivikko A, Koller DY, Niggemann B, Norberg LA, Urbanek R, Valovirta E, Wahn U: Pollen immunotherapy reduces the development of asthma in children with seasonal rhinoconjunctivitis (the PAT-study). J Allergy Clin Immunol 2002;109:251-256. 
7 Bousquet J, Lockey R, Malling HJ: Allergen immunotherapy: therapeutic vaccines for allergic diseases. A WHO position paper. J Allergy Clin Immunol 1998;102:558-562.

$\checkmark 8$ Pichler CE, Helbling A, Pichler WJ: Three years of specific immunotherapy with house-dust-mite extracts in patients with rhinitis and asthma: significant improvement of allergen-specific parameters and of nonspecific bronchial hyperreactivity. Allergy 2001;56:301-306.

9 Wahn U, Tabar A, Kuna P, Halken S, Montagut A, de Beaumont O, Le Gall M: Efficacy and safety of 5-grass-pollen sublingual immunotherapy tablets in pediatric allergic rhinoconjunctivitis. J Allergy Clin Immunol 2009;123:160-166.

10 Durham SR, Emminger W, Kapp A, Colombo G, de Monchy JG, Rak S, Scadding GK, Andersen JS, Riis B, Dahl R: Long-term clinical efficacy in grass pollen-induced rhinoconjunctivitis after treatment with SQ-standardized grass allergy immunotherapy tablet. J Allergy Clin Immunol 2010;125: 131-138.

11 Valenta R, Niederberger V: Recombinant allergens for immunotherapy. J Allergy Clin Immunol 2007;119:826-830

12 Egger M, Hauser M, Himly M, Wopfner N, Wallner M, Ferreira F: Development of recombinant allergens for diagnosis and therapy. Front Biosci 2009;1:77-90.

13 Pauli G, Larsen TH, Rak S, Horak F, Pastorello E, Valenta R, Purohit A, Arvidsson M, Kavina A, Schroeder JW, Mothes N, Spitzauer S, Montagut A, Galvain S, Melac M, Andre C, Poulsen LK, Malling HJ: Efficacy of recombinant birch pollen vaccine for the treatment of birch-allergic rhinoconjunctivitis. J Allergy Clin Immunol 2008;122:951960.

14 Pauli G, Malling HJ: The current state of recombinant allergens for immunotherapy. Curr Opin Allergy Clin Immunol 2010;10: 575-581.

15 Asturias JA: Recombinant hypoallergens for immunotherapy of Parietaria judaica pollen allergy. Front Biosci 2009;14:4606-4617.

16 Thomas WR, Hales BJ, Smith WA: Genetically engineered vaccines. Curr Allergy Asthma Rep 2005;5:197-203.

17 Moingeon P, Batard T, Fadel R, Frati F, Sieber J, Van Overtvelt L: Immune mechanisms of allergen-specific sublingual immunotherapy. Allergy 2006;61:151-165.

18 Allam JP, Novak N, Fuchs C, Asen S, Berge S, Appel T, Geiger E, Kochan JP, Bieber T: Characterization of dendritic cells from human oral mucosa: a new Langerhans' cell type with high constitutive FcepsilonRI expression. J Allergy Clin Immunol 2003;112: 141-148.

19 Allam JP, Wurtzen PA, Reinartz M, Winter J, Vrtala S, Chen KW, Valenta R, Wenghoefer M, Appel T, Gros E, Niederhagen B, Bieber T, Lund K, Novak N: Phl p 5 resorption in human oral mucosa leads to dose-dependent and time-dependent allergen binding by oral mucosal Langerhans cells, attenuates their maturation, and enhances their migratory and TGF-betal and IL-10-producing properties. J Allergy Clin Immunol 2010;126: 638-645.

20 Allam JP, Bieber T, Novak N: Dendritic cells as potential targets for mucosal immunotherapy. Curr Opin Allergy Clin Immunol 2009;9:554-557.

21 Mascarell L, Lombardi V, Louise A, Saint-Lu $\mathrm{N}$, Chabre H, Moussu H, Betbeder D, Balazuc AM, Van Overtvelt L, Moingeon P: Oral dendritic cells mediate antigen-specific tolerance by stimulating $\mathrm{TH} 1$ and regulatory CD4+ T cells. J Allergy Clin Immunol 2008; 122:603-609.

22 Pittner G, Vrtala S, Thomas WR, Weghofer M, Kundi M, Horak F, Kraft D, Valenta R: Component-resolved diagnosis of housedust mite allergy with purified natural and recombinant mite allergens. Clin Exp Allergy 2004;34:597-603.

23 Weghofer M, Thomas WR, Kronqvist M, Mari A, Purohit A, Pauli G, Horak F, Grönlund $H$, van Hage $M$, Valenta $R$, Vrtala $S$ : Variability of IgE reactivity profiles among European mite allergic patients. Eur J Clin Invest 2008;38:959-965.

24 Thomas WR, Smith W-A, Hales BJ, Mills KL, O'Brien RM: Characterization and immunobiology of house dust mite allergens. Int Arch Allergy Immunol 2002;129:1-18.

25 Scala E, Alessandri C, Bernardi ML, Ferrara R, Palazzo P, Pomponi D, Quaratino D, Rasi C, Zaffiro A, Zennaro D, Mari A: Cross-sectional survey on immunoglobulin $\mathrm{E}$ reactivity in 23,077 subjects using an allergenic molecule-based microarray detection system. Clin Exp Allergy 2010;40:911-921.

$\checkmark 26$ Hales BJ, Shen H, Thomas WR: Cytokine responses to Der p 1 and Der p 7: house dust mite allergens with different IgE-binding activities. Clin Exp Allergy 2000;30:934-943.

-27 Martínez J, Eraso E, Palacios R, Guisantes JA: Cross-reactions between Dermatophagoides pteronyssinus and Dermatophagoides farinae (Acari: Pyroglyphidae) related to the different growth phases of cultures. J Med Entomol 2000;37:35-39.

28 Yasueda H, Mita H, Yui Y, Shida T: Comparative analysis of physicochemical and immunochemical properties of the two major allergens from Dermatophagoides pteronyssinus and the corresponding allergens from Dermatophagoides farinae. Int Arch Allergy Appl Immunol 1989;88:402-407.

29 Takai T, Takaoka M, Yasueda H, Okumura $\mathrm{K}$, Ogawa H: Dilution method to refold bacterially expressed recombinant Der f 2 and Der $\mathrm{p} 2$ to exhibit the secondary structure and histamine-releasing activity of natural allergens. Int Arch Allergy Immunol 2005; 137:1-8.

30 Hakkaart GA, Harmsen MM, Chua KY, Thomas WR, Aalberse RC, Van Ree R: Expression of the house dust mite allergen Der p 2 in the baker's yeast Saccharomyces cerevisiae. Clin Exp Allergy 1998:28:45-52.

-31 Tanyaratsrisakul S, Malainual N, Jirapongsananuruk O, Smith WA, Thomas WR, Piboonpocanun S: Structural and IgE binding analyses of recombinant Der p 2 expressed from the hosts Escherichia coli and Pichia pastoris. Int Arch Allergy Immunol 2009;151:190-198.

-32 Lienard D, Tran Dinh O, van Oort E, Van Overtvelt L, Bonneau C, Wambre E, Bardor M, Cosette P, Didier-Laurent A, de Borne FD, Delon R, van Ree R, Moingeon P, Faye L, Gomord V: Suspension-cultured BY-2 tobacco cells produce and mature immunologically active house dust mite allergens. Plant Biotechnol J 2007;5:93-108.

33 Smith WA, Hales BJ, Jarnicki AG, Thomas WR: Allergens of wild house dust mites: environmental Der $p 1$ and Der $\mathrm{p} 2$ sequence polymorphisms. J Allergy Clin Immunol 2001;107:985-992.

- 34 Park JW, Kim KS, Jin HS, Kim CW, Kang DB, Choi SY, Yong TS, Oh SH, Hong CS: Der p 2 isoallergens have different allergenicity, and quantification with 2-site ELISA using monoclonal antibodies is influenced by the isoallergens. Clin Exp Allergy 2002;32: 1042-1047.

35 Piboonpocanun S, Malainual N, Jirapongsananuruk O, Vichyanond P, Thomas WR: Genetic polymorphisms of major house dust mite allergens. Clin Exp Allergy 2006;36: 510-516.

36 Batard T, Hrabina A, Bi XZ, Chabre H, Lemoine P, Couret M-N, Faccenda D, Villet B, Harzic P, André F, Goh SY, André C, Chew FT, Moingeon P: Production and proteomic characterization of pharmaceutical-grade Dermatophagoides pteronyssinus and Dermatophagoides farinae extracts for allergy vaccines. Int Arch Allergy Immunol 2006; 140:295-305.

- 37 Bussieres L, Bordas-Le Floch V, Bulder I, Chabre H, Nony E, Lautrette A, Berrouet C, Nguefeu Y, Horiot S, Baron-Bodo V, Van Overtvelt L, De Conti AM, Schlegel A, Maguet N, Mouz N, Lemoine P, Batard T, Moingeon P: Recombinant fusion proteins assembling Der $\mathrm{p} 1$ and Der $\mathrm{p} 2$ allergens from Dermatophagoides pteronyssinus. Int Arch Allergy Immunol 2010;153:141-151.

- 38 Batard T, Didierlaurent A, Chabre H, Mothes $\mathrm{N}$, Bussieres L, Bohle B, Couret MN, Ball T, Lemoine P, Focks Tejkl M, Chenal A, Clement G, Dupont F, Valent P, Krauth MT, Andre C, Valenta R, Moingeon P: Characterization of wild-type recombinant Bet $\mathrm{v}$ la as a candidate vaccine against birch pollen allergy. Int Arch Allergy Immunol 2005;136:239-249.

39 Himly M, Nony E, Chabre H, Van Overtvelt L, Neubauer A, van Ree R, Buchheit KH, Vieths S, Moingeon P, Ferreira F: Standardization of allergen products. 1. Detailed characterization of GMP-produced recombinant Bet v 1.0101 as biological reference preparation. Allergy 2009;64:1038-1045. 
-40 Yang JT, Wu CS, Martinez HM: Calculation of protein conformation from circular dichroism. Methods Enzymol 1986;130:208269.

-41 Burtin D, Chabre H, Olagnier B, Didierlaurent $\mathrm{A}$, Couret $\mathrm{MN}$, Comeau $\mathrm{D}$, Wambre $\mathrm{E}$, Laparra H, Van Overtvelt L, Montandon F, Batard T, Jonval V, Lorphelin A, Merle C, Berrouet C, Parry L, Gomord V, Van Ree R, Moingeon P: Production of native and modified recombinant Der p 1 molecules in tobacco plants. Clin Exp Allergy 2009;39:760770 .

42 Razafindratsita A, Saint-Lu N, Mascarell L, Berjont N, Bardon T, Betbeder D, Van Overtvelt L, Moingeon P: Improvement of sublingual immunotherapy efficacy with a mucoadhesive allergen formulation. J Allergy Clin Immunol 2007;120:278-285.

43 Mueller GA, Benjamin DC, Rule GS: Tertiary structure of the major house dust mite allergen Der p 2: sequential and structural homologies. Biochemistry 1998;37:1270712714.

44 Derewenda U, Li J, Derewenda Z, Dauter Z, Mueller GA, Rule GS, Benjamin DC: The crystal structure of a major dust mite allergen Der $\mathrm{p} 2$, and its biological implications. J Mol Biol 2002;318:189-197.
45 Penagos M, Compalati E, Tarantini F, BaenaCagnani R, Huerta J, Passalacqua G, Canonica GW: Efficacy of sublingual immunotherapy in the treatment of allergic rhinitis in pediatric patients 3 to 18 years of age: a metaanalysis of randomized, placebo-controlled, double-blind trials. Ann Allergy Asthma Immunol 2006;97:141-148.

46 Ferreira F, Briza P, Infuhr D, Schmidt G, Wallner M, Wopfner N, Thalhamer J, Achatz G: Modified recombinant allergens for safer immunotherapy. Inflamm Allergy Drug Targets 2006;5:5-14.

47 Moingeon P: Sublingual immunotherapy: from biological extracts to recombinant allergens. Allergy 2006;61(suppl 81):15-19.

48 Chua KY, Huang CH, Shen HD, Thomas WR: Analysis of sequence polymorphism of a major mite allergen, Der p 2. Clin Exp Allergy 1996;26:829-837.

49 Lynch NR, Thomas WR, Chua Y, Garcia N, Di Prisco MC, Lopez R: In vivo biological activity of recombinant Der $p$ II allergen of house-dust mite. Int Arch Allergy Immunol 1994;105:70-74.

50 Mueller GA, Smith AM, Williams DC, Jr., Hakkaart GA, Aalberse RC, Chapman MD, Rule GS, Benjamin DC: Expression and secondary structure determination by NMR methods of the major house dust mite allergen Der p 2. J Biol Chem 1997;272:2689326898 .
51 Asturias JA, Ibarrola I, Arilla MC, Vidal C, Ferrer A, Gamboa PM, Viñuela J, Sanz ML, Andreu C, Martínez A: Engineering of major house dust mite allergens Der $\mathrm{p} 1$ and Der $\mathrm{p}$ 2 for allergen-specific immunotherapy. Clin Exp Allergy 2009;39:1088-1098.

52 Hakkaart GA, Chapman MD, Aalberse RC, van Ree R: Immune-reactivity of recombinant isoforms of the major house dust mite allergen Der p 2. Clin Exp Allergy 1998;28: 169-174.

53 Smith AM, Chapman MD: Reduction in IgE binding to allergen variants generated by site-directed mutagenesis: contribution of disulfide bonds to the antigenic structure of the major house dust mite allergen Der p 2. Mol Immunol 1996;33:399-405.

54 Smith AM, Chapman MD, Taketomi EA, Platts-Mills TA, Sung SS: Recombinant allergens for immunotherapy: a Der $\mathrm{p} 2$ variant with reduced IgE reactivity retains T-cell epitopes. J Allergy Clin Immunol 1998;101: $423-425$.

55 van 't Hof W, Driedijk PC, van den Berg M, Beck-Sickinger AG, Jung G, Aalberse RC: Epitope mapping of the Dermatophagoides pteronyssinus house dust mite major allergen Der p II using overlapping synthetic peptides. Mol Immunol 1991;28:1225-1232. 